\title{
Efficient Outcomes by a New Technique SIMBO- FDTD for Skin Cancer Detection
}

\section{Shelendra Pal ( $\nabla$ shelendra.pal12@gmail.com )}

Gurukula Kangri University: Gurukul Kangri (Deemed to be University) https://orcid.org/0000-00015568-7282

\section{Rajkumar}

Gurukula Kangri University: Gurukul Kangri (Deemed to be University)

DR Vipul Sharma

Gurukula Kangri (Deemed to be University) Faculty of Engineering and Technology

\section{Research Article}

Keywords: FDTD, SIMBO optimization, Skin Cancer detection, K-means Clustering

Posted Date: August 25th, 2021

DOI: https://doi.org/10.21203/rs.3.rs-820716/v1

License: (c) (1) This work is licensed under a Creative Commons Attribution 4.0 International License. Read Full License 


\title{
Efficient Outcomes by a new technique SIMBO-FDTD for Skin Cancer Detection
}

\author{
Shelendra Pal ${ }^{a^{*}}$, Rajkumar ${ }^{\mathrm{b}}$, Vipul Sharma ${ }^{\mathrm{c}}$ \\ ${ }^{a, b}$ Department of Computer Science, Faculty of Technology, Gurukula Kangri
}

(Deemed To Be University), Haridwar, India

Email: shelendra.pal12@gmail.com, rajbhatia@gkv.ac.in

${ }^{c}$ Department of Electronics and Communication Engineering and Technology, Gurukula Kangri (Deemed To Be University), Haridwar, India

\section{Email: vipul.s@gkv.ac.in}

\begin{abstract}
Cancer is one of the most common diseases affecting humans globally of which skin cancer is one. Formerly, medical imaging techniques are designed to provide physicians with information about the body and out-of-body diseases and for their intended diagnosis. By identifying and treating the exact location of a patient's cancer cells, the patient's chances of survival greatly increase and are currently used for various classification problems. However, to achieve accurate and simple future performance, yet to be achieved and Correct treatment based on its accurate prognosis will be an important step in the evaluation of disease outcomes. At this time, freezing, axial surgery, MOH surgery, curettage, and electro dissection or cryotherapy, radiation therapy, chemotherapy, photodynamic therapy, biological therapy are several corrective tools for its treatment. The main objective of this research paper is the development of skin cancer detection techniques using finite difference time domain(FDTD) using various computer image techniques and the research paper suggests that the technique being designed has the primary ability to better diagnose skin cancer than any other current investigator.
\end{abstract}

Keywords: FDTD, SIMBO optimization, Skin Cancer detection, K-means Clustering

\section{Introduction}

Malignant development perhaps a second massive incentive to start to travel around the world [1] and a study by the yank Cancer Society (ACS) suggests that around 600,920 individuals in 2017 will certainly kick the bucket from tumors within the Accordingly, fighting malignant development could be a major check that any man of science and center specialist takes into account[3]. the first position takes on a vital role in distinguishing between malignant development and might boost as a result of stamina rates were running it slow earlier. The detection and finding of early diseases is a crucial technique for clinical imaging. As is recognizable, clinical imaging was wide used for pharmaceutical products[4] for early detection, monitoring, associated follow-up of malignant growth. However, manual translation of a huge time of clinical images is often tedious and long, and ultimately human inclination and mistakes. computer aided ID structures (CAD) were conjointly valueadded within the primary one 980s to assist specialists to decrypt clinical pictures to extend their intensity [5].

The unwellness is that the ensuing world driver of death with a measurable 9.6 million deaths in 2018. Universally, malignant development is because of one in the vi passages. simply twenty-six of low-pay countries reportable with insurance widely obtainable in the public domain in2014,2016,2015. as compared to below 30\% of low-wage economies, over 90\% of the large remuneration nations revealing care administrations are given. The monetary influence of malignancy is central and rising. In 2010 gross annual malignancy financial expense was calculated at roughly US\$1.16 trillion [6]. only one of 5 low and center-paid countries have the information required to push the malignant strategy [7]. In low- and middle pay nations regarding seventy p.c of the transfers of malignant development take place. Around half the malignant growth, the syndrome is attributed to five of the most social and diagnostic hazards of malignant development: a high weight list, a decreased intake of leaves, lack of a working condition, smoking, or liquor use. Tobacco use is the most important danger concern for malignant development and accounts for around $22 \%$ of disease events[8,9]. Contaminating malignancies infected with 
unstoppable infections and human papillomavirus (HPV) is responsible for up to $25 \%$ of low- and centrally-paid introduction at the later stage and unavailable information and care is usually given[10].

\section{Materials \& Methods}

Method and Material can be divided here 3 parts like FDTD, Kmeans and SIMBO.

\subsection{FDTD}

FDTD the procedure can straightforwardly cover Maxwell's terms of time subjection. Over the most recent ten years, FDDT innovation has pulled in the consideration of individuals in numerical cycles utilized in electromagnetic perceptions. Its fundamental fascination lies in the rudiments, what's more, FDTD is volume-based Transform is right now disintegrated into deceptive parts utilizing Fourier change structure strategy. This favored area makes FDTD especially appropriate for most EMC issues, as it is normal to amend these issues. The FDTD methodology is a volume-based procedure that requires a uniform framework made out of masterminded space cells. At every pixel, the $\mathrm{E}$ and $\mathrm{H}$ locale fragments will be described. This read of FDDT innovation isn't entirely unexpected from FEM. Nonetheless, a structure condition is framed in FEM, which might be handled later severally. inside the FDTD procedure, no lattice format is required. when everything is that the equivalent, the $\mathrm{E}$ and $\mathrm{H}$ areas are befuddled in space, and consequently the normal hop procedure is utilized. this empowers the extension to be coordinated in a convenient way. At the tip of the day, with the progression of time, the answer to each handle segment will be parsed at the exact time expected and spared. the improvement of FDTD will be upheld the unusual segment of the Yee cell that keeps the $\mathrm{E}$ and $\mathrm{H}$ field fragments in 0.5 and isolates them. This supports an adequately right differential plan, which will be referenced beneath. FDTD: FDTD relies upon the replay point of the math, and FDTD portrayals aren't trademark. Most clearly, (1) successful FDTD relies upon the exact exhibition of the primary flexibly of entertainment energy (2) to hinder exact truncation and truncation measures (3) to be a great deal of exact, it's a strong field improving plan. that thinks about the measure of ranches inside the region outside the FDTD methodology to help the space. despite the fact that there are important components that affect reactivation, the fundamental meaning of FDTD is at the tip of this point. a high-level view is given as an example of the centrality of blunders created by each procedure including total FDTD diversion.

Once the computational area and the lattice material are built up, the excitation or source is determined. The source can be an impinging plane wave, a current on a wire, or an expected contrast. Since the E and H fields are resolved legitimately, the yield of the recreation is normally the $\mathrm{E}$ or $\mathrm{H}$ field at a point or a progression of focuses inside the computational area, or the $\mathrm{E}$ or $\mathrm{H}$ field at specific focuses, saw as for time [11][12][13].

Time dependent differential equations are given by,

$$
\begin{gathered}
\varepsilon \frac{\partial \vec{E}}{\partial x}=\nabla \times \vec{H} \\
\mu \frac{\partial \vec{H}}{\partial x}=-\nabla \times \vec{E}
\end{gathered}
$$

Where $\mathrm{H}$ is the magnetic field, $\mathrm{E}$ is the electric field, $\mu$ is the magnetic permeability $\varepsilon$ is the electric permittivity. For the purpose of FDTD simulations, $\mathrm{H}$ and $\mathrm{E}$ fields are unknown and all other quantities are given at each point in space. The scalar Eq. (1) expending curl vector into three Eq. (1a,1b,1c) and from Eq. (2) also expending into three subs partial differential Eq. $(2 \mathrm{a}, 2 \mathrm{~b}, 2 \mathrm{c})$ shown below, for example, the derivative of the $\mathrm{x}, \mathrm{y}, \mathrm{z}$ component of the electric field with respect to time is given by,

$$
\begin{aligned}
& \varepsilon_{x} \frac{\partial E_{x}}{\partial t}=\frac{\partial H_{z}}{\partial y}-\frac{\partial H_{y}}{\partial z} \\
& \varepsilon_{y} \frac{\partial E_{y}}{\partial t}=\frac{\partial H_{x}}{\partial z}-\frac{\partial H_{z}}{\partial x} \\
& \varepsilon_{z} \frac{\partial E_{z}}{\partial t}=\frac{\partial H_{y}}{\partial x}-\frac{\partial H_{x}}{\partial y} \\
& \mu_{x} \frac{\partial H_{x}}{\partial t}=\frac{\partial E_{y}}{\partial z}-\frac{\partial E_{z}}{\partial y} \\
& \mu_{y} \frac{\partial H_{y}}{\partial t}=\frac{\partial E_{z}}{\partial x}-\frac{\partial E_{x}}{\partial z} \\
& \mu_{z} \frac{\partial H_{z}}{\partial t}=\frac{\partial E_{x}}{\partial y}-\frac{\partial E_{y}}{\partial x}
\end{aligned}
$$

As such way we can derived FDTD 2d

The decrease of Maxwell's equation 2-dimensional space is helpful for acquiring the arrangements of numerous issues. In all likelihood, however, 2-dimensional conditions are utilized where the supposition that is made that the field is invariant in one of the 3 spatial measurements. When the improvement of the FDTD in a 2-dimensional period is noted, the speculation to the 3-dimensional space will be simpler to follow. 
Expecting field invariableness in the z-direction, Maxwell's equations diminish to two potential arrangements of equalizations. During the discussion, aggression was adopted with respect to the Z-axis, so Transverse magnetic (TM) or Transverse electrical (TE) polarization is performed regarding one of the following directions.

Maxwell's equations reduce to Transverse Magnetic polarization,

$$
\begin{aligned}
& -\mu \frac{\partial H_{x}}{\partial t}=\frac{\partial E_{z}}{\partial y} \\
& \mu \frac{\partial H_{y}}{\partial t}=\frac{\partial E_{z}}{\partial x} \\
& \frac{\partial E_{z}}{\partial t}=\frac{1}{\varepsilon}\left(\frac{\partial H_{y}}{\partial x}-\frac{\partial H_{x}}{\partial y}-\sigma E_{z}\right)
\end{aligned}
$$

Other stands for Transverse Electric polarization,

$$
\begin{aligned}
& \frac{\partial E_{x}}{\partial t}=\frac{1}{\varepsilon}\left(\frac{\partial H_{z}}{\partial y}-\sigma E_{x}\right) \\
& \frac{\partial E_{y}}{\partial t}=-\frac{1}{\varepsilon}\left(\frac{\partial H_{z}}{\partial x}+\sigma E_{y}\right) \\
& \frac{\partial H_{z}}{\partial t}=\frac{1}{\mu}\left(\frac{\partial E_{x}}{\partial y}-\frac{\partial E_{y}}{\partial x}\right)
\end{aligned}
$$

An immediate answer for the frameworks in Eq. (3) sub equation to and in Eq. (4) sub equations involves a change of the differential conditions to a lot of contrast conditions utilizing a focal distinction guess plan to the spatial and worldly subsidiaries. In the wake of applying the leap-frog measure on these equalizers. Finally, got the Transverse Magnetic polarization conditions following,

$$
\begin{gathered}
H_{x}^{n+\frac{1}{2}}(i, j)=H_{x}^{n-\frac{1}{2}}(i, j)-\frac{\Delta t}{\mu_{i j} \Delta y}\left[E_{z}^{n}(i, j+1)-E_{z}^{n}(i, j)\right] \\
H_{y}^{n+\frac{1}{2}}(i, j)=H_{y}^{n-\frac{1}{2}}(i, j)+\frac{\Delta t}{\mu_{i j} \Delta x}\left[E_{z}^{n}(i+1, j)-E_{z}^{n}(i, j)\right] \\
E_{z}^{n+1}(i, j)=E_{x}^{n}(i, j)+\frac{\Delta t}{\varepsilon_{i j} \Delta x}\left[H_{y}^{n+\frac{1}{2}}(i+1, j)-H_{y}^{n+\frac{1}{2}}(i, j)\right]-\frac{\Delta t}{\varepsilon_{i j} \Delta y}\left[H_{x}^{n+\frac{1}{2}}(i, j+1)-H_{x}^{n+\frac{1}{2}}(i, j)\right]
\end{gathered}
$$

Likewise, for the Transverse Electric polarization case,

$$
\begin{gathered}
E_{x}^{n+\frac{1}{2}}(i, j)=E_{x}^{n-\frac{1}{2}}(i, j)+\frac{\Delta t}{\varepsilon_{i j} \Delta y}\left[\left(H_{z}^{n}(i, j+1)-H_{z}^{n}(i, j)\right]\right. \\
E_{y}^{n+\frac{1}{2}}(i, j)=E_{y}^{n-\frac{1}{2}}(i, j)-\frac{\Delta t}{\varepsilon_{i j} \Delta x}\left[\left(H_{z}^{n}(i+1, j)-H_{z}^{n}(i, j)\right]\right. \\
H_{z}^{n+1}(i, j)=H_{z}^{n}(i, j)+\frac{\Delta t}{\mu_{i j} \Delta y}\left[E_{x}^{n+\frac{1}{2}}(i, j+1)-E_{x}^{n+\frac{1}{2}}(i, j)\right]-\frac{\Delta t}{\mu_{i j} \Delta x}\left[E_{y}^{n+\frac{1}{2}}(i+1, j)-E_{y}^{n+\frac{1}{2}}(i, j)\right]
\end{gathered}
$$

where permittivity $\left(\varepsilon_{i j}\right)$ and permeability $\left(\mu_{i j}\right)$ of each cell in the grid.

An air-filled rectangular cavity resonator is a model having perfect electric conductor boundary conditions. The cavity's length, width, and height are $10.0 \mathrm{~cm}$ in X-direction, $4.8 \mathrm{~cm}$ in Y-direction, and $2.0 \mathrm{~cm}$ in the z-direction, respectively. The simulation model is gridded 50x24x10 in $\mathrm{x}, \mathrm{y}$, and $\mathrm{z}$ directions individually. The cavity is excited at $(24,12,5.12)$ location in grids, with differential Gaussian pulse given by $\mathrm{J}(\mathrm{t})=\mathrm{J}_{0} *\left(\mathrm{t}-\mathrm{t}_{0}\right) * \exp \left(-\left(\mathrm{t}-\mathrm{t}_{0}\right)^{\wedge} 2 / \mathrm{tau}^{\wedge} 2\right)$, where tau $=50$ per sec.

The difference in electrical properties of tumor tissues and ordinary tissues can be misused utilizing microwaves for the location of the disease. The greater part of the investigates toward this path has been accomplished for the identification of bosom malignant growth while works committed to skin disease location are not many. In this work, an earnest exertion has been done toward this path. SIMBO-FDTD talked about and approved in the past area has been utilized as a recreation device.

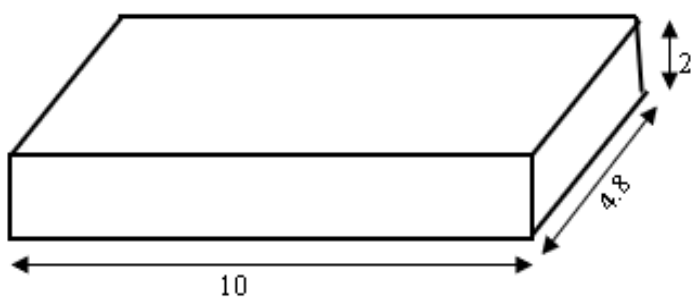

Fig. 11 Picture of Rectangular Cavity

Fig. 1 represent a $10.0 \mathrm{~cm} \times 4.8 \mathrm{~cm} \times 2 \mathrm{~cm}$ rectangular piece of the relative dielectric consistent 4.2 and conductivity $0.16 \mathrm{~S} / \mathrm{m}$ is utilized to invigorate skin tissues of the human body. Of this section upper $2 \mathrm{~cm}$ thickness is devoted to skin epidermis with dielectric steady 44 and conductivity $1.54 \mathrm{~S} / \mathrm{m}$. The remainder of the section is committed to the dermis and hypodermis comprising of generally greasy tissues. To recreate tumor tissue, a little 2D shape with dielectric steady 50 and conductivity $7 \mathrm{~S} / \mathrm{m}$ having measurement $0.2 \mathrm{~cm} \times 0.2 \mathrm{~cm} \times 0.2 \mathrm{~cm}$ is set at $26 \times 24 \times 5$ area in the section at the interface of dermis and epidermis. The structure is enlightened with a $4 \mathrm{GHz}$ separated Gaussian heartbeat episode at $(30,24)$ area. the process of simulation is moved including and in absentia, tumor tissue embedded inboard the frame. Dispersed electric field esteems can be recorded to see the reaction. The aftereffects of the re-enactment appear in (Fig. 3) and (Fig. 4). Contrasting Fig. 3 and 4 at the time step 30 , the tumor tissue is effectively noticeable. 


\subsection{K-Means Cluster}

The next approximation is the nearest calculation for the neighbor. It is also known as sparkling learning, when there is no ambiguous expectation to soak up previous information [19]. k-means is one of the simplest non-regulated classification problems solving learning algorithms. The method is based on a straightforward and simple way to identify a certain set of data in a series of clusters (assuming k clusters). K centers should be created, which are one for each cluster. These centers can be put in a cunning manner because of different location stimuli. Therefore, the only option is to keep them as far as possible apart. The next step is to connect each data point to the nearest center. The first period is completed and the early group age is completed if there is no item in store. $\mathrm{K}$ new centroids from the previous stage should be recalculated as a barycenter of the clusters. New connections between the same data centers and the nearest new center must be formed once these new centers. Finally, it attempts to minimize an objective function known as the squared error function given by

$$
J(v)=\sum_{i=1}^{c} \sum_{j=1}^{c_{i}}\left(\left\|x_{i}-v_{i}\right\|\right)^{2}
$$

Where The Euclidean distance around $\mathrm{xi}$ and $\mathrm{Vt}$ is given by '\|xi - Vt\|'

' $c_{i}$ ' is the sum of knowledge concentrated in the community $\mathrm{i}^{\text {th }}$ and ' $c$ ' is the group focal quantity.

Let the datasets be $\mathrm{X}=\{\mathrm{x} 1, \mathrm{x} 2, \mathrm{x} 3, \ldots, \mathrm{xn}\}$, and the focuses are set to $\mathrm{V}=\{\mathrm{v} 1, \mathrm{v} 2, \ldots \ldots ., \mathrm{vc}\}$. The focuses.

i. Pick 'c' bunch focuses indiscriminately.

ii. Measuring the distance between each group and the information point center.

iii. Grant a group community information point, with at least all bunch places good ways from the group.

iv. Use the new bunch center recalculate:

$$
\text { a. } v_{i=}\left(1 / c_{i}\right) \sum_{j=1}^{c_{i}} x_{i}
$$

Where the $c_{i}$ in the group compares to the quantity of information focuses.

v. Recalculating the good ways from the gathered bunch habitats to every information point.

vi. If no reassigned information point, stop, rehash from stage 3)

\subsection{SIMBO}

The harmony between the investigation of the pursuit space and misuse of possibly great arrangements is considered as a central issue in nature-motivated frameworks. An excess of weight on investigation brings about an unadulterated arbitrary hunt though a lot of abuse brings about an unadulterated locality search. The keen inquiry should progressively consolidate investigation of the new areas of the space with an assessment of potential arrangements previously distinguished. The proposed SIMBO variations are prepared to do progressively consolidate the investigation and abuse practices in the streamlining cycle. The treatment is balanced progressively during their streamlining cycle so as to adjust the investigation and misuse trade-offs. The dynamic transformation system empowers the SIMBO alterations to squabble up with complicated multimodal hunt scenes productively.

A small piece of information, taken from the SIR model of swine flu [22-24], expanded the SIMBO. For example, divided into three parts, SIR Consolidated Immunization and Treatment, isolation, and disconnection involved in basic SIR and SIR goes to create SIMBO-T, SIMBO-V, and SIMBO-Q as shown in figures 2. These models have been used in the experimental method of this thesis.

\begin{tabular}{|c|c|}
\hline \multicolumn{2}{|r|}{ Nomenclature are used in SIMBO } \\
\hline Day & Recent repetition(iteration) or Day \\
\hline$T_{d}$ & Total number of days repetitions (iterations) \\
\hline$T_{i}$ & Total number of persons (population size) \\
\hline $\mathrm{S}$ & State Individual Position \\
\hline $\mathrm{H}$ & Well-being or Health (Fitness) \\
\hline$P_{s}$ & Pandemic state (the finest state in population) \\
\hline$P_{h}$ & Pandemic health (Fitness value associated with $\mathrm{P}_{\mathrm{s}}$ ) \\
\hline $\mathrm{V}$ & Swine flu vaccine \\
\hline Dose & Antiviral medicines to fix swine influenza \\
\hline$\mu$ & Vaccination possibility or probability \\
\hline$\alpha$ & Recovery possibility or probability \\
\hline$\beta$ & Quarantine possibility or probability \\
\hline$M_{d}$ & Dose for the Momentum factor \\
\hline$M_{s}$ & State for the Momentum factor \\
\hline
\end{tabular}

Table 1 Symbol and Variables for SIMBO

\section{Procedure of SIMBO-V}




\subsubsection{Health Check-Up}

A person's health depends on the fitness function given above. For the clinical confirmation of swine flu, in the beginning, the health of each person is evaluated and all susceptible patients are examined.

\subsubsection{First Aid or Treatment}

Treatment depends on manifestations and is regularly founded on experimentation. A doctor by and large starts the treatment with a commonplace portion and screens for a reaction just as results.

The normalization of the portion depends on the populace portion reaction attributes and not on individual ideal results [20,21]. At the point when the portion is acclimated inevitably relying upon the singular criticism then the ideal outcome is arrived at faster. Same as the fundamental SIMBO calculations (for example SIMBO-T, SIMBO-V, and SIMBOQ) likewise having the measure of portion dependent on essential indications, optional symptom, current wellbeing and pandemic wellbeing where the essential manifestations and auxiliary side effects appear in Eq. (7) and Eq. (8).

$$
\text { Primary (Day) }=(\mathrm{Fe} * \mathrm{Co} * \text { FateHead } * \mathrm{NV} * \text { Dai }) * \mathrm{e}^{-\frac{\mathrm{TD}}{\text { Day }}}
$$

Where Fe stands for Fever, likewise Cough-Co, Fatigue, and headache- FateHead, Nausea, Vomiting- NV, and DiarrheaDai. The initial term in (1) is the whole impact of essential side effects and the subsequent term is expanding the essential manifestation every day.

$$
\text { Secondary(Day) }=1-\mathrm{e}^{-\operatorname{primary}(\text { Day })}
$$

The dose supplied to the individual is given by equation (3).

$$
\begin{aligned}
\text { Dose }_{m+1}= & \text { Dose }_{m} * \mathrm{Md} * \text { Primary }(\text { Day }) * \operatorname{rand} *\left(1-\frac{\text { PresentDayHealth }_{m}}{\operatorname{rand} * \mathrm{Ph}}\right) \\
& + \text { Secondary }_{\text {Day }} * \operatorname{rand} *\left(\text { PresentDayHealth }_{m}-\mathrm{P}_{h}\right)
\end{aligned}
$$

later advancement in the health of the unique does is lessening because of the last terms in Eq. (9) as the current wellbeing of individuals is closer to pandemic wellbeing. The force factor is used in proceeding with the treatment and state of the individual self. For implementing the treatment, the likelihood of recuperation utilized is $\alpha=0.2$ Being the part of the proposed work, the change is fused in the wake of computing the dose it is checked for its incentive with the assistance of reach and restricted it to the possible reach. With this controlled dose, the individual state gets changed as demonstrated in Eq. (10).

$$
S_{m}=S_{m}+M_{s} * \text { Dose }_{m+1}
$$

Here $M_{s}$ and $M_{d}$ are the non-direct energy factors, these confine the person's treatment and state inside as far as possible without checking the wellbeing consistently. Similarly, the strength of an individual falls apart, a dose of the medication increments, or an extra dose is included. $P_{h}$ is pandemic well-being that relates to best wellness esteem which further compares to the best pandemic state i.e., $P_{s}$.

\subsubsection{SIMBO-V}

The model of SIMBO-V is introduced in Fig. (2). It plays out the advancement through inoculation and treatment dependent on likelihood. At first, everybody is accepted as susceptible on the grounds that one contaminated individual in the populace prompts the absolute populace vulnerable. The vulnerable populace can get the contamination on presentation to an affirmed instance of swine flu test inside the irresistible time of 10 days post introduction. All clinically defenseless people ought to go for a swine flu test. After an affirmed instance of pig vent in the network, the defenseless are encouraged to go for the pig pipe immunization to secure resistance to pig pipe afterward. The treatment is given to all people in the populace by differing antiviral medications relying on current wellbeing. The SIMBO-V performs streamlining through four fundamental strides as given beneath. These four stages will proceed until all ages are finished. Stage 1 and 4 of SIMBO-V is the same as SIMBO-T. The means 2 and 3 are clarified underneath.

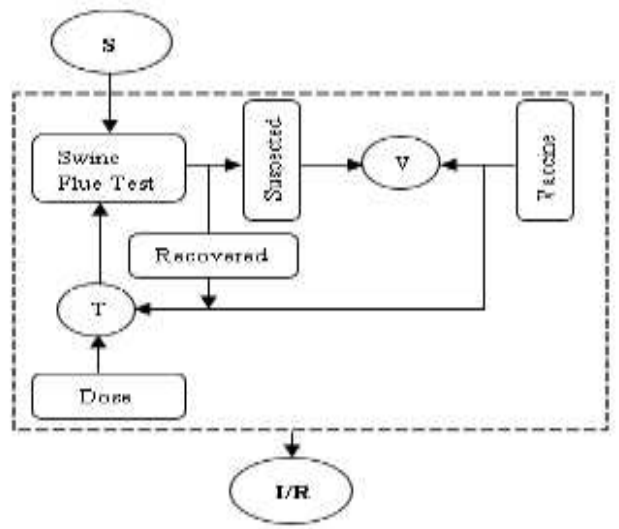

Fig. 2 Replica Of SIMBO-Vaccine 


\subsubsection{VACCINATION}

SIMBO-V uses an immune function to optimize susceptible cases and then treats confirmed cases in the population. Vaccination is performed by multiplying the person's condition by a random value in a probability-based range (0-1) Vaccination and treatment under normal conditions depend on the possibility of recovery, and people with poor health (that is, the problem's health score at least high) below the dynamic threshold will be affected. Swine flu. $50 \%$ of the best population use dynamic adjustment threshold value given by the following equation

$$
\text { D_Threshold }=\text { mean }\left(\text { PresentDayHealth }_{m}\left(1-\frac{T_{i}}{2}\right) * \operatorname{rand} * \operatorname{Primary}(\text { Day })\right)
$$

By multiplying probability of vaccination $(\mu)$, random value (rand), and the probability of adapting to the majority of people in the main symptom population, the average fitness score here can be reduced. In SIMBO-V, an appropriate mechanism must be used to identify the vaccine that has been vaccinated, because the vaccine can only be vaccinated once in a lifetime. This is presenting the variety every which way in the populace and furthermore keeping the person in the region to the first bunch of the populace. This is accomplished with the assistance of the equation (6) demonstrated as follows

$$
V c=1.5 * \text { rand }-0
$$

Therefore, SIMBO-V behaves like SIMBO-T in the final stages because vaccination has been done for each person.

\section{Results and Discussion}

In this section, discuss about the experiment, Fig. (3) as a normal skin and Fig.(4) as a skin malignant tissue shown following. To get picture improvement, the Region of Interest (ROI) based planning has been used. Starting with the image improvement, Fig. (5) changed to greyscale as shown in Fig.(6). By ROI masking window with masking $>174$ is applied until that, which gives results showed up in Fig.(7). The ROI window is furthermore restricted with 185>masking value(I) $>177$ and the results have shown up in Fig. (8) has obtained. A spread for explicit pixels, addressing tumor tissues, is created using the make shroud limit of MATLAB. By then, this cover is copied to the image that showed up in Fig. (8) to improve the picture of the issue. Results are as showed up in Fig. (9) as a skin tumor.
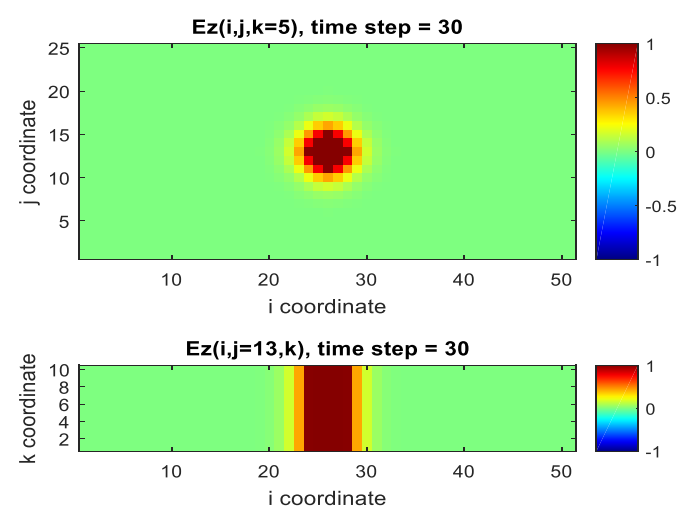

Fig. 3 Result for normal skin on a simulator
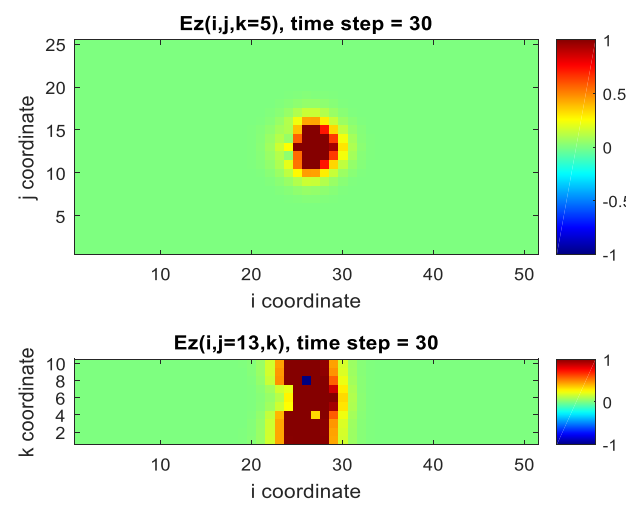

Fig. 4 Result for cancer tissue in the skin on a simulator

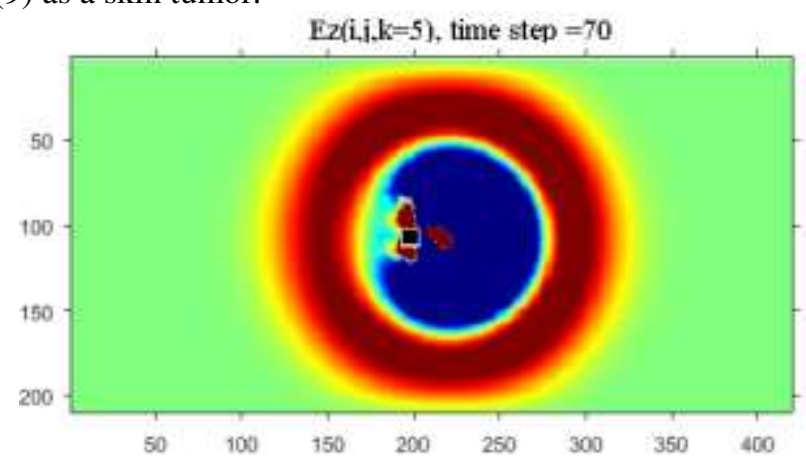

Fig. 5 Simulation for Skin cancer tissue under the grid position

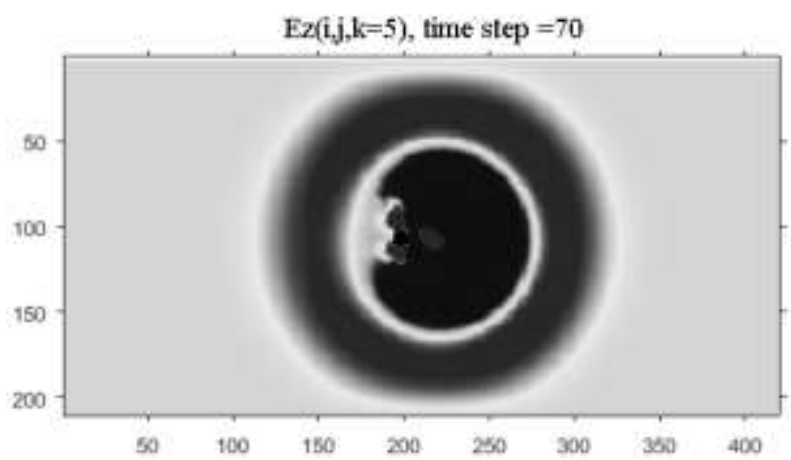

Fig. 6 Gray format image for Skin Cancer tissue 


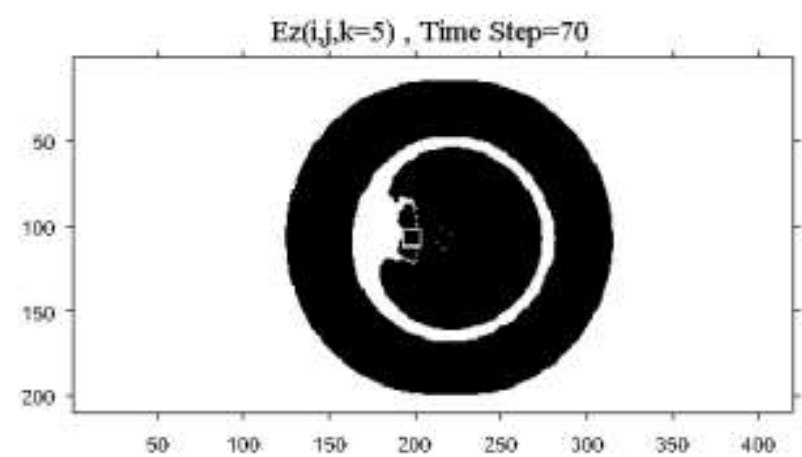

Fig. 7. Use of ROI for skin image enhancement of cancer tissue

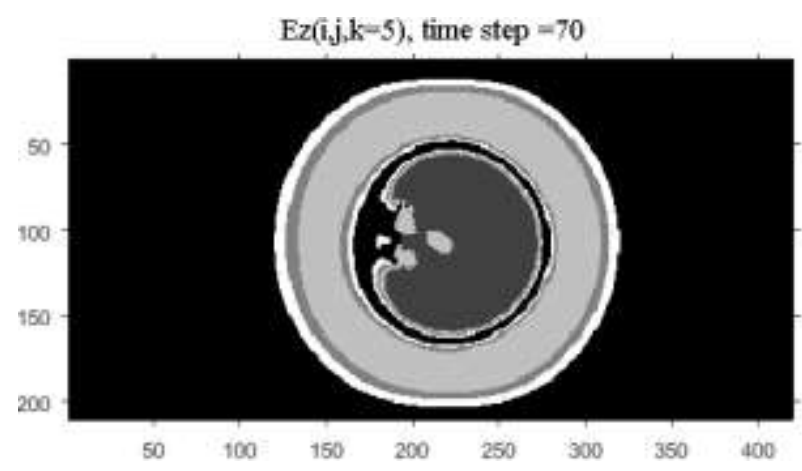

Fig. 8 Masking for skin image enhancement of cancer tissue

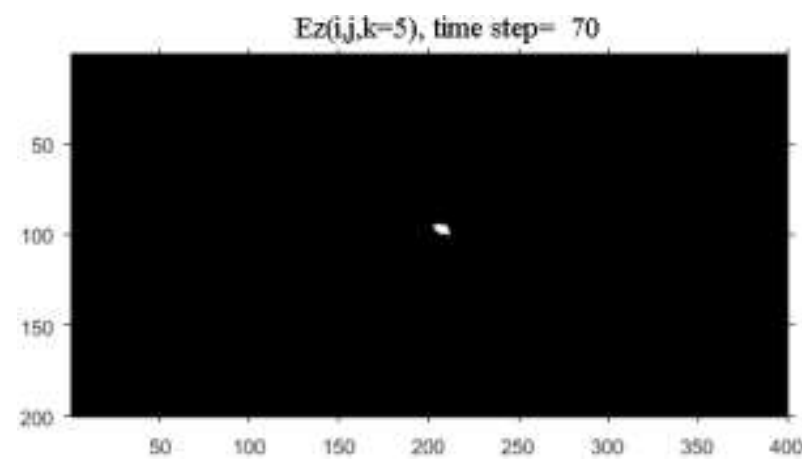

Fig. 9 After Applying the ROI mask on the Cancer tissue image

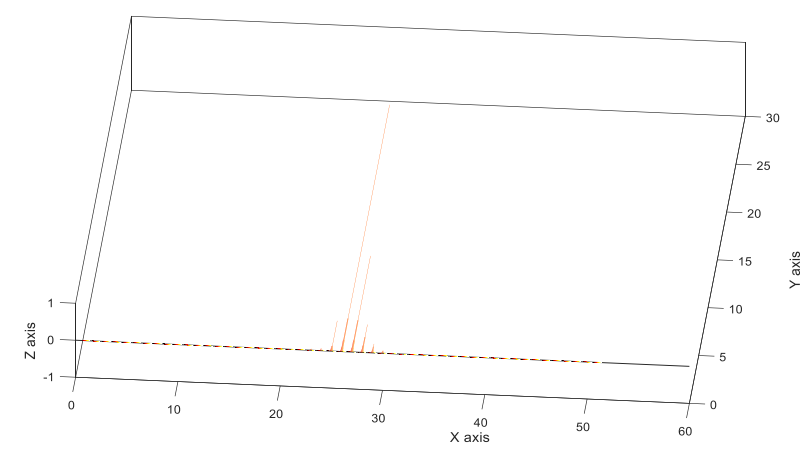

Fig. 10 Cancer tissue spreading along with every axis

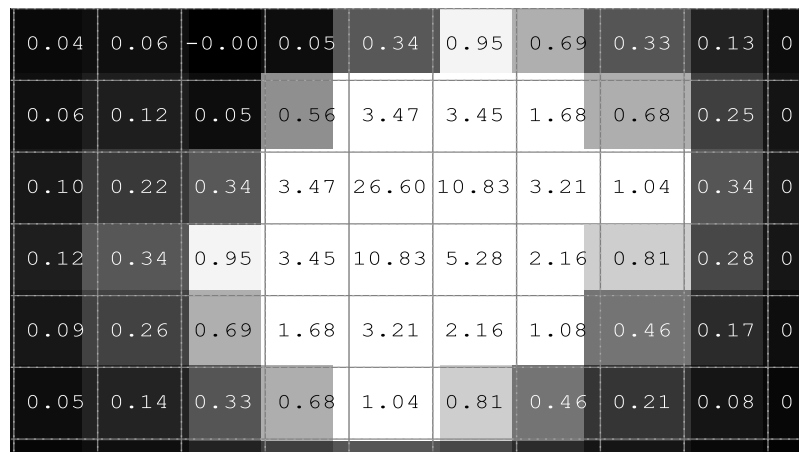

Fig. 11 Pixel value with corresponding above image

\section{Conclusions}

The diligent decline in the illness demise rate since 1991 has achieved an overall drop of $29 \%$, changing over into generally 2.9 million less threat passing. This predictable progression is for the most part a result of diminishes in smoking and following reductions in cell breakdown in the lungs mortality, which have revived starting late. Before long, progress is moving back for tumors that are agreeable to early disclosure through screening (ie, chest sickness, prostate threat, and CRC), and critical racial and geographic aberrations proceed for particularly preventable dangerous developments, for instance, those of the cervix and lung. Extended interest in both the unprejudiced usage of existing infectious prevention mediations and major and clinical investigation to extra advancement treatment decisions would unmistakably animate advancement against harmful development.

\section{Conflict of interest}

The authors confirm that this article content has no conflicts of interest. 


\section{References}

[1] L.A. Torre, F. Bray, R.L. Siegel, J. Ferlay, J. Lortet-Tieulent,(2015), “A. Jemal, Global cancer statistics”, 2012, CA: a cancer journal for clinicians, vol- 65, 87-108.

[2] Cancer facts \& figures 2017, American Cancer Society, 2017, (2017).

[3] R.L. Siegel, K.D. Miller, (2016), “A. Jemal, Cancer statistics”, 2016, CA: a cancer journal for clinicians, 66 ,7-30.

[4] L. Fass, Imaging and cancer: a review, Molecular oncology, 2 (2008) 115-152.

[5] K. Doi, Computer-aided diagnosis in medical imaging: historical review, current status and future potential, Computerized medical imaging and graphics, 31 (2007) 198-211.

[6] Stewart BW, Wild CP, editors. World cancer report 2014 Lyon: International Agency for Research on Cancer; 2014.

[7] Global Initiative for Cancer Registry Development. International Agency for Research on Cancer

[8] GBD 2015 Risk Factors Collaborators. Global, regional, and national comparative risk assessment of 79 behavioural, environmental and occupational, and metabolic risks or clusters of risks, 1990-2015: a systematic analysis for the Global Burden of Disease Study 2015. Lancet. 2016 Oct; 388 (10053):1659-1724.

[9] Ferlay J, Soerjomataram I, Ervik M, Dikshit R, Eser S, Mathers C et al. GLOBOCAN 2012 v1.0, Cancer Incidence and Mortality Worldwide: IARC CancerBase No. 11 Lyon, France: International Agency for Research on Cancer; 2013.

[10] Plummer M, de Martel C, Vignat J, Ferlay J, Bray F, Franceschi S. Global burden of cancers attributable to infections in 2012: a synthetic analysis. Lancet Glob Health. 2016 Sep;4(9):e609-16. doi: 10.1016/S2214-109X(16)30143-7.

[11] Chaudhary SS, Mishra RK, Swarup A, Thomas JM, (1984), "Dielectric properties of normal \& malignant human breast tissues at radiowave \& microwave frequencies", Indian J Biochem Biophy, vol-21, pp.76-79.

[12] Shams R, Sadeghi P, (2011), “On optimization of finite-difference time-domain (FDTD) computation on heterogeneous and GPU clusters”, J Parallel Distrib Comput ,vol -71(4), pp. 584-93.

[13] Vipul Sharma, S.S. Pattnaik, "Microwaves, Metamatetrial and Skin Cancer Detection" LAP LAMBERT Academic Publishing Germany Jan (2014).

[14] A Taflove, (1995) "Computational Electrodynamics: The Finite-Difference Time-Domain Method, 3rd Edition", Boston, MA: Artech House.

[15] A. Taflove and M. Brodwin,, (1975), "Numerical solution of steady state electromagnetic scattering problems using the time-dependent Maxwell's equations”, IEEE Trans. Microw. Theor. Tech,vol -23, pp. 623-730.

[16] M. Celuch-Marcysiak and W. K. Gwarek, (1999), “On the nature of solutions produced by finite difference schemes in time domain”,International Journal of Numerical Modelling: Electronic Networks,Devices and Fields, vol-12(1-2), pp.2340 .

[17] Chu S. T and Chaudhuri S. K (1995), ,(2004) "FDTD method for optical waveguide analysis", Progress in electromagnetic research, PIER 11,255-300. Hung Loui , 1D-FDTD using MATLAB, Student Member, IEEE.

[18] Lantz, B. (n.d.). Machine learning with R. 2nd ed. Birmingham: Packt Publishing, pp. 65-87, 89-124, 225-231, 239-247, 293-311, 315-324.

[19] Tom M. Mitchell, Machine Learning, McGraw-Hill Science/Engineering/Math; (March 1, 1997), pp 52-75, 156-177, 230-244

[20] S. S. Pattnaik, K. M. Bakwad, B. S. Sohi, R. K. Ratho and S. Devi, (2013), "Swine Influenza Model Based Optimization”, Journal of Applied Soft Computing, vol-13(1), pp. 628-653.

[21] D. G. Jadhav, S. S. Pattnaik and S. Das, (2014), "Memetic Algorithm with Local Search as Modified Swine Influenza Model Based Optimization and its uses in ECG Filtering”, Journal of Optimization, vol-2, pp. 1-22.

[22] B. J. Coburn, B. G. Wagner, S. Blower, (2009), "Modeling influenza epidemics and pandemics: insights into the future of swine flu (H1N1)”, BMC Medicine, pp.7-30.(DOI:10.1186/1741-7015-7-30).

[23] Anupam Biswas, K. K.Mishra, Shailesh Tiwari, and A. K. Misra, (2013), "Physics-Inspired Optimization Algorithms: A Survey", Journal of Optimization, Article ID- 438152, pp.16, DOI:10.1155/2013/438152.

[24] J. Arino, F. Brauer, P. van den Driessche, J. Watmough, J. Wu, (2008), “A model for influenza with vaccination and antiviral treatment", Journal of Theoretical Biology, 253, pp.118-130. 